\title{
A Summary of Research on Self-Confidence and Its Role in the Students
}

\author{
ShuJuan Zhao ${ }^{1^{*}}$, ShiQing $\mathrm{Wei}^{1}$, JunQian $\mathrm{Luo}^{2}$, JianMin $\mathrm{Chen}^{3}$ \\ ${ }^{1}$ Jose Rizal University,0900, Education Management, Manila, Philippines \\ 2 The First People's Hospital of JINZHONG, 030600, ShanXi, China \\ ${ }^{3}$ WenZhou Polytechnic, Wenzhou, ZheJiang, 325035, China \\ Email: jennyzhao625@yahoo.com
}

\begin{abstract}
Self-confidence is an important part of personality, which plays an important role in the formation of individual personality. This article comprehensively discusses self-confidence from the five aspects of self-confidence research history, self-confidence definition, self-confidence theoretical research analysis, relationship between self-confidence and mental health, and self-confidence research in the student population, then put forward a new outlook for the study of self-confidence.
\end{abstract}

Keywords: self-confidence, history and development, student psychology

\section{Introduction}

Self-confidence is an important part of personality and plays an important role in the formation of individual personality. Faced with challenges, self-confidence will enhance the individual's courage and determination, more flexible to deal with and solve difficulties. Self-confidence is an important psychological mechanism for human adaptation to society [1]. Self-confidence expresses the degree to which an individual believes that he is capable, important and valuable, and shows the individual's confidence in his ability, identity, achievement and value [2,3]. This self-identification plays an important role in individual psychological activity and psychological development [4].

Therefore, the study of self-confidence has always been deeply loved by the field of Education and Psychology. Psychologists have carried out research and practice on self-confidence from various angles.

\section{History of Self-Confidence Study}

The study of self-confidence can be traced back to as early as 1890, when the philosopher William James put forward "believe in yourself" in the discussion in "Principles of Psychology". At the same time, Dr. Frederick Needham's speech at the opening of the psychology section of the British Medical Journal mentioned a way to enhance the self-confidence of mental patients by providing "freedom". Played a powerful role in promoting rehabilitation. [5]

During the First World War, psychologists believed that self-confidence can greatly relieve nervousness and reduce fear [6]. Whether during the climax of the prohibition society reform movement in the 1920s [7] or during the Great Depression, psychologists are aware of the impact of self-confidence on individual life [8]. In 1943, Maslow, a humanist psychologist, pointed out that self-esteem comes from confidence. He believes that once an individual gains self-confidence, he has a desire for "self-actualization" [9]. After World War II, the rapidly developing economy has largely met people's material needs. A large number of studies on self-confidence have begun to appear in society, and many self-confidence-related concepts such as self-esteem and self-efficacy have been proposed. [10, 11, 12, 13]

\section{Definition of Self-Confidence}

Due to the different perspectives of self-confidence, the definition of self-confidence is also different.

As early as 1943, Maslow defined "confidence". He believes that self-esteem is an emotional experience that arises when self-esteem needs to be satisfied, and points out that lack of respect will lead to depression 
and inferiority. Copper smith. S(1976) believes that self-confidence is a positive subjective evaluation of an individual, and believes that he is capable and valuable; Rosenberg (1979) believes that self-confidence is affirmation of self-ability; Jackson.MR (1984) believes that the state changes of self-esteem with the external environment; Chinese scholar Che Wen Bo (1985) believes that self-confidence is a self-intention for individuals to believe in their abilities and energy [14]; Shrauger (1990) believes that self-confidence is a subjective evaluation of their own effective response to the environment; Huang Xi Ting (1991) believes that self-confidence is an individual's summary of past successful experiences [15].;Zhang Chun Xing 's Zhang 's Dictionary of Psychology (Dong Hua Bookstore, 1992) believes that self-confidence refers to personal trust in oneself and confidence in what one knows and can do; Corey (1993) believes that selfconfidence is a positive subjective perception way; Dickstein (1997) believes that self-confidence is a sense of self-efficacy; Branden (1998) believes that self-confidence is a judgment of the ability to feel happiness. Yan Guo Cai (1999) pointed out that self-confidence is to believe in yourself and believe that the goal you are pursuing is Correctly, I also believe that I have the power and ability to achieve the correct goal that I am pursuing; Yang Li Zhu (2000) believes that self-confidence is a positive experience of feeling one's own abilities and values; Che Li Ping (2002) believes that self-confidence is an individual. The degree of affirmation in all aspects of oneself is a stable character of objective, correct cognition and evaluation of one's own ability and value. Self-confident people can look up and believe in themselves, and dare to meet challenges and move towards success [16].

The differences in the focus and methods adopted by researchers on self-confidence research fully reflect the diversified definitions of self-confidence and the richness of its connotation and extension.

\section{Theoretical Analysis of Self-Confidence Research}

Self-confidence is an important quality and personality of a person. Many psychologists have conducted theoretical exploration and analysis of self-confidence.

\subsection{Viewpoint of Humanistic Psychology}

\subsubsection{The view of Allport G.W.}

Psychologist Allport pointed out that a sense of security refers to an individual's complex attitude towards the environment, including confidence in self, confidence in things, trust in people, and the ability to endure setbacks and misfortunes in life. Having a sense of security is an essential quality of a healthy personality [17]. It can be seen that self-confidence is an important factor in the formation of personality.

\subsubsection{The view of Maslow A.H.}

Maslow suggested that self-confidence is an emotional experience that arises when self-esteem needs are satisfied. It makes people feel that they are valuable, powerful, capable, positional, useful and necessary in this world. People without such self-confidence will feel so helpless [18]. Maslow believes that once people meet the needs of self-esteem, they begin to log in to the door of self-realization [18].

\subsection{Cattell R.B.'s Theory of Trait Factor Theory}

Cattell R.B. believes that the basic structural elements of personality are traits. The so-called traits refer to a certain form of behavior and consistency that people maintain in different times and situations. This personality structure can be inferred from the individual's behavior. There are many types of personality traits, and temperament traits are determined by heredity. They are expressed as a person's style, such as emotional type, speed, impulsiveness, dominance, sensitivity and self-confidence. It can be seen that self-confidence is one of the characteristics of the basic structural elements of personality.

\subsection{The New Psychoanalytic Perspective}

\subsubsection{Bandura's self-efficacy theory}

Bandura put forward the definitions of self-efficacy and self-efficacy beliefs. He believes that self-efficacy is the perception of behavioral operation ability and the belief about guarding self-generation ability. Self- 
efficacy beliefs have functions similar to cognition, motivation, and emotion. They are a powerful force in human behavior operations. They have inestimable and alternative value in controlling and regulating behaviors [19].

\subsubsection{Yoder J. the view of "Five Major Self-Confidence Crisis"}

Influenced by Eric Eriksson's view on "identity and life cycle", psychologist Yoder summarized the development of childhood self-confidence into five major transition periods based on his own observations, also known as "five self-confidence crisis". It includes a basic period of trust (0-2 years); a traumatic transition from infancy to toddler stage (2-3 years); sibling competition period (4-5 years); peer competition period (5, 6-12, 13 years old) and the War of Independence (13-19 years old) [20]. In the process of growth, everyone will experience crisis of self-confidence.

\section{The Relationship between Self-Confidence and Personal Physical and Mental Health}

Self-confidence is not only conducive to promoting the individual's mental health, but also an important sign of the individual's mental health development. Studies have shown that individuals with high selfconfidence levels have a high level of physical and mental health [21]. In terms of self-regulation, selfconfidence is positively related to motivation for achievement [22]. Individuals with high self-confidence level have less interpersonal trouble [23]. Individuals have different levels of self-confidence, and also have characteristics of complexity, clarity and stability. These cognitive structural features of self-confidence have a buffering effect on mental illness, depression, anxiety, etc. [24] Studies have shown that the certainty of self-confidence components and internal harmony have a predictive effect on mental health [25]. Individuals cannot form a complete self-evaluation out of the social process. In the process of forming self-confidence, individuals form their own anchors through self-comparison and social comparison. Individuals form self-anchors through self-comparison and social comparison [26].

\section{Self-Confidence in Student Groups}

In 2006, Jonsson discussed the relationship between self-confidence and many variables such as violence, drug use, bullying, relationships, and academic achievement. Studies have shown that people with strong self-confidence play an important role in academic achievement, social and personal responsibility (Naderi, Abdullah, Aizan, Sharir \& Kumar, 2009). Some psychologists have tracked and surveyed hundreds of teenagers with high levels of intellectual development, living conditions and educational conditions that are roughly the same. The results of the study show that individual psychological stereotypes play an important role in the process of success. Those who have a more stable self-affirmed inner tendency tend to have a greater success rate than those with more self-negative tendencies. Self-confidence as a positive and internal motivation, its development level corresponds to the success or failure of the activity.

Confidence plays a significant role in students' learning. Students with higher level of academic confidence are proved to be high achievers. Internal motivation is an important component in improving students' academic confidence (Georgiou's, 1999). It has been found that the child who perceives himself confident has a high level of academic achievement. The child who perceives himself as worthless is less confident and may not come up to the optimum level of attainment (Stevens, 2005). Students with low academic confidence enter college with lower academics skill and are found to be less engaged and face more transition difficulties (Shoemaker, 2010; Sander \& Sanders, 2005).

In recent years, the psychological health of college students has attracted social attention. The Federation of Malaysian Employers (2009) stated that the problem faced by employers in hiring fresh graduates is a lack of self-confidence, especially in terms of rapport with the business community, especially soft skills in communication skills.

The Survey of Gallup \& Strada College Student in 2017 has found that college students are experiencing a "crisis of confidence" about their future careers. Here are some key findings from the study, which surveyed more than 32,000 college students at 43 four-year colleges. Major Study Finds College Students Lack Confidence about their Future Success. 
Chinese scholars have also done a lot of researches on the self-confidence of college students. In 2009, research by Liu Wei et al. Showed that a considerable proportion of college students have insufficient selfconfidence, and the proportion is as high as 30-40\%, and even some students have a strong sense of inferiority [27].

Zhang Minting's full-time sample survey of 408 college students at Han Shan Teachers College showed that college students' self-confidence scores showed significant differences in differences in individual birthplaces, grades, whether the individual was an only child, and whether they were normal students [31].

In May 2018, Yu Sheng Nan and others used cluster stratified sampling to randomly select 640 students from a medical college in Fujian for questionnaire survey. The results showed that medical students' selfconfidence scores ranged from 11 to 39 , with an average score of (28.73 \pm 4.35$)$. Among them, 10-15 points (inferiority complex) 7 people $(1.1 \%), 16-25$ points (self-perception) 126 people (19.7\%), 26-35 points (confidence) 459 people (71.8\%), 43 people (6.7\%) with 36-40 points (super confident) [32].

The lack of self-confidence has a great negative impact on college students' study, life, growth and future. Understanding the level of self-confidence of college students and promoting their self-confidence is a problem that the whole society cannot ignore. There are many scholars discussing the role of group psychology in enhancing the self-confidence of college students, but due to limited conditions, some samples are small [33, 34], some lack strict control, some only do investigations, and no intervention studies of intervention studies only and lack of basis for investigation [34]

In summary, the origin and development of self-confidence research both play an important role in individual and even social development. It is an important field that society must pay attention to and an important subject that individual development must face. Judging from the current survey data, the self-confidence level of the group is not optimistic, and it must arouse widespread concern in the society, and can propose intervention programs and improvement methods in a targeted manner, starting from the starting point of education and starting from the long-term development of the individual. The improvement and development of individual self-confidence provides a free, harmonious, optimistic and positive social environment.

\section{References}

1. Johnson D \& Fowler J H. The evolution of overconfidence. Nature, 2011,477(7364): 317-320

2. Bi Chong Zeng. Cultivation of self-confidence character. Hefei: Anhui Education Press, 2009

3. Shen Zhuo Qing, Dong Yan, Yu Guoliang. The theoretical model of information difference in overconfidence. Psychological Science, 2009, 32 (6): 1405-1407

4. Che Li Ping, Huang Xi Ting. Research on the theoretical construction of self-confidence of young college students. Psychological Science, 2006, 29 (3): 563-569

5. Snyder, C. R.; Lopez, Shane J. (2009-01-01). Oxford Handbook of Positive Psychology. Oxford University Press. ISBN 978-0-19-518724-3.

6. Bird, Charles (1917-01-01). "From Home to the Charge: A Psychological Study of the Soldier". The American Journal of Psychology. 28 (3): 315-348. doi:10.2307/1413607. JSTOR 1413607.

7. Wheeler, Mary P. (1918-01-01). "Alcohol and Social Case Work". The Annals of the American Academy of Political and Social Science. 77: 154-159. doi:10.1177/000271621807700116. JSTOR 1014456.

8. Eisenberg, P.Lazarsfeld, P. F. (1938-06-01). "The psychological effects of unemployment". Psychological Bulletin. 35 (6): 358-390. doi:10.1037/h0063426. ISSN 1939-1455.

9. Maslow, A. H. (1943-07-01). "A theory of human motivation". Psychological Review. 50(4): 370-396. CiteSeerX 10.1.1.334.7586. doi:10.1037/h0054346. ISSN 1939-1471.

10.Greenwald, A. G., \& Banaji, M. R. (1995-01-01). "Implicit social cognition: Attitudes, self-esteem, and stereotypes". Psychological Review. 102 (1): 4-27. CiteSeerX 10.1.1.411.2919. doi:10.1037/0033-295X.102.1.4. ISSN 1939-1471.

11. Bénabou, Roland; Tirole, Jean (2005-01-01). Agarwal, Bina; Vercelli, Alessandro (eds.). Psychology, Rationality and Economic Behaviour. International Economic Association Series. Palgrave Macmillan UK. pp. 19-57. CiteSeerX 10.1.1.179.119. doi:10.1057/9780230522343_2. ISBN 9781349521449.

12. Bandura, Albert (1997-02-15). Self-Efficacy: The Exercise of Control. Macmillan. ISBN 978-0-7167-2850-4.

13. Baumeister, Roy F.; Campbell, Jennifer D.; Krueger, Joachim I.; Vohs, Kathleen D. (2003-05-01). "Does High Self-Esteem Cause Better Performance, Interpersonal Success, Happiness, or Healthier Lifestyles?". Psychological Science in the Public Interest. 4 (1): 1-44. doi:10.1111/1529-1006.01431. ISSN 1529-1006. PMID 26151640. 
14. Che Wen Bo. Humanistic Psychology [M]. Hangzhou: Zhejiang Education Press. 2003: 40-48.

15. Bi Chong Zeng, Huang XiTing. The connotation and function of confident personality in Chinese culture [J]. Advances in Psychological Science, 2007, 15 (0 2): 224 - 229.

16. Che Li Ping. The concept of self-belief, research on the mechanism of mind and function [J]. Journal of the Southwest Normal University (Science and Humanities Society), 2002,28 (0 2): 86-89.

17. Kernis M H, Grannemann B D \& Mathis L C. Stability of self-esteem as a moderator of the relation be- tween level of self-esteem and depression. Journal of Personality and Social Psychology, 1991, 61(1): 80- 92.

18. Maslow A H. A theory of humanm otivation. Psychological Review, 1943, 370-396.

19. Gao Jian Jiang, "Bandula on the Formation and Development of Self-efficacy", Psychological Science, $1992,39$.

20. Jean Yoder, William Proctor. The self-confident child. New York: The United States of America, Facts on file publications, 1988, 18-33.

21. Bi ChongZeng, Huang XiTing. Confidence and Health. Research and Practice of Health Care Medicine, 2008, 5 (1): 4-8

22. Huang Yu, Pan Yun, Huang Ya Hu. Research on the relationship between self-confidence and achievement motivation of college students in independent colleges. Research and Practice of Health Medicine, 2012, 9 (3): 1921.

23. Feng Jin. A review of psychological resilience research. Journal of Southwest University (Social Science Edition), 2012, 38 (2): 1-7.

24. Zhang Ji Yuan, Bi Chong Zeng. The relationship between self-confidence and interpersonal distress: the intermediary effect of clarity. Journal of Southwest University (Natural Science Edition), 2012, 34 (8): 145-148.

25. Bi Chong Zeng, Huang Xi Ting. Confidence and Health. Research and Practice of Health Care Medicine, 2008, 5 (1): $4-8$.

26. Bi Chong Zeng, Huang Xi Ting, Dou Gang. A preliminary study on the classification of self-confidence of young students.

27. Liu Wei, Research on the Effect of Centralized and Closed Group Consultation on Improving the Self-confidence of University Students, Chinese Journal of Clinical Psychology. 2009.03: 381-382

28. Zhang Zhijun, Correlation analysis of self-confidence of college students and family upbringing, Journal of Ankang University, 2011,8 (23): 4.

29. Zhu Chuan Lin, Qi Zheng Yang, Cheng Juan, Li Ping, Li Shui Xia, Wang Wei, Survey Report on Self-confidence Level of College Students. Social Psychological Science. 2015, 5 (30): 58-61.

30. Ms.R.Maheswari And Dr.K.Maheswari,A Study On Self-Esteem Among The College Students, IOSR Journal of Humanities And Social Science (IOSR-JHSS) Volume 21, Issue 10, Ver. 8 (October.2016) PP 08-10.

31. Zhang Minting, Characteristics and Related Research of College Students' Self-Confidence and Social Support, Theoretical Research, 2018, 03: 36-38.

32. Yu Sheng Nan, Xiao Hui Xin, Deng Shang Qing, Research on the correlation between self-worth and self-confidence of medical students, China Higher Medical Education, 2018, 5:27.

33. Hu Yue, Research on the Effect of Structured Growth Groups on the Confidence Building of College Students. 2019, 6 (25): 43-44

34. Liu Wei, Wen Bin, Lv Jing, Xie Gang, Li Xiaobo, Zhou Xing lin. Research on the effect of centralized and closed group consultation on improving the self-confidence of college students. Chinese Journal of Clinical Psychology. 2009.17 (3): 381. 